\title{
Leonid Feoktistovich Chernogor (on His 60th Birthday)
}

DOI: $10.1134 / \mathrm{S} 0016793210060150$

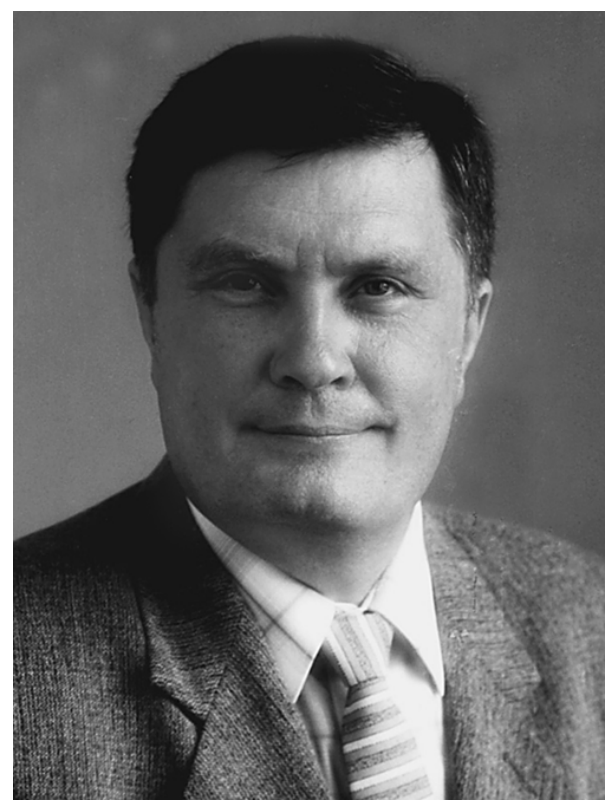

Leonid Feoktistovich Chernogor is a renown geophysicist and radiophysicist, Dr. Sci. (Phys.-Math.), and a laureate of the Ukrainian SSR State Prize in the field of science and engineering (1989), as well as two USSR Council of Ministers prizes and a prize of the USSR Ministry of Higher and Secondary-Trade Education.

Leonid Feoktistovich Chernogor was born in the Kharkov area (Ukraine) on June 2, 1950. He graduated with honors from the radiophysics faculty of
Kharkiv State University (1972), and he defended his Cand. Sci. (Phys.-Math.) dissertation in 1975 and Dr. Sci. (Phys.-Math.) dissertation in 1987. He was elected a member of the Academy of Sciences of Applied Radioelectronics of Belorussia, Russia, and Ukraine (1993) and a member of the Academy of Sciences of Higher Learning of Ukraine (2005).

Currently, his scientific interests are related to problems in space radiophysics, remote radio-sensing of the atmosphere and geocosmos, physics of highenergy phenomena in the Earth-atmosphere-ionosphere-magnetosphere (EAIM) system, and active experiments in this system. He formulated and developed a conception that the EAIM formation is an open dynamic system, investigated the mechanisms of interaction between subsystems, determined the excitation thresholds, and studied the manifestations of trigger mechanisms in subsystems.

As early as the 1980 s, he experimentally revealed and theoretically explained (discovered) the theretofore unknown phenomenon of the emergence of large-scale (more than $1000 \mathrm{~km}$ ) disturbances in the near-Earth plasma and geomagnetic field, caused by the influence of powerful non-steady-state radiowave radiation on the ionosphere.

Chernogor is the author of 17 books (including tutorials), more than 600 academic works, and an author and coauthor of many papers in our journal.

We truly congratulate Leonid Feoktistovich on his jubilee and wish him good health and further successes in science. 